\title{
Index of Insurance-Related Services
}

Automobile Wreckers see Salvage Factors Directory Services 45

Engineering Consultants see Investigating Consultants and Forensics

Environmental Consultants 38, 49

Forensic Accountants 4, 5, 13, 17, 25,

33, 35, 37, 49, 63, See also Insurance

Loss Accountants
Insurance Counsel 4, 6, 11, 13, 18, 34, 36, $39,40,44,46,50,59,63,69,70$

Insurance Loss Accountants 5, 7, 14, 26,

37, 40, 42, 52, 65

Investigating Consultants and Forensics 26, 54

Restoration Services 11, 12, 14

Salvage Factors 55, 65

\section{Index of Insurance Associations and Governing Bodies}

Canadian Independent Adjusters'

Association 146

Fire Marshals and Fire Commissioners

in Canada 148

Insurance Associations 144
Ontario Insurance Adjusters Association 152

Superintendents of Insurance in Canada 150 


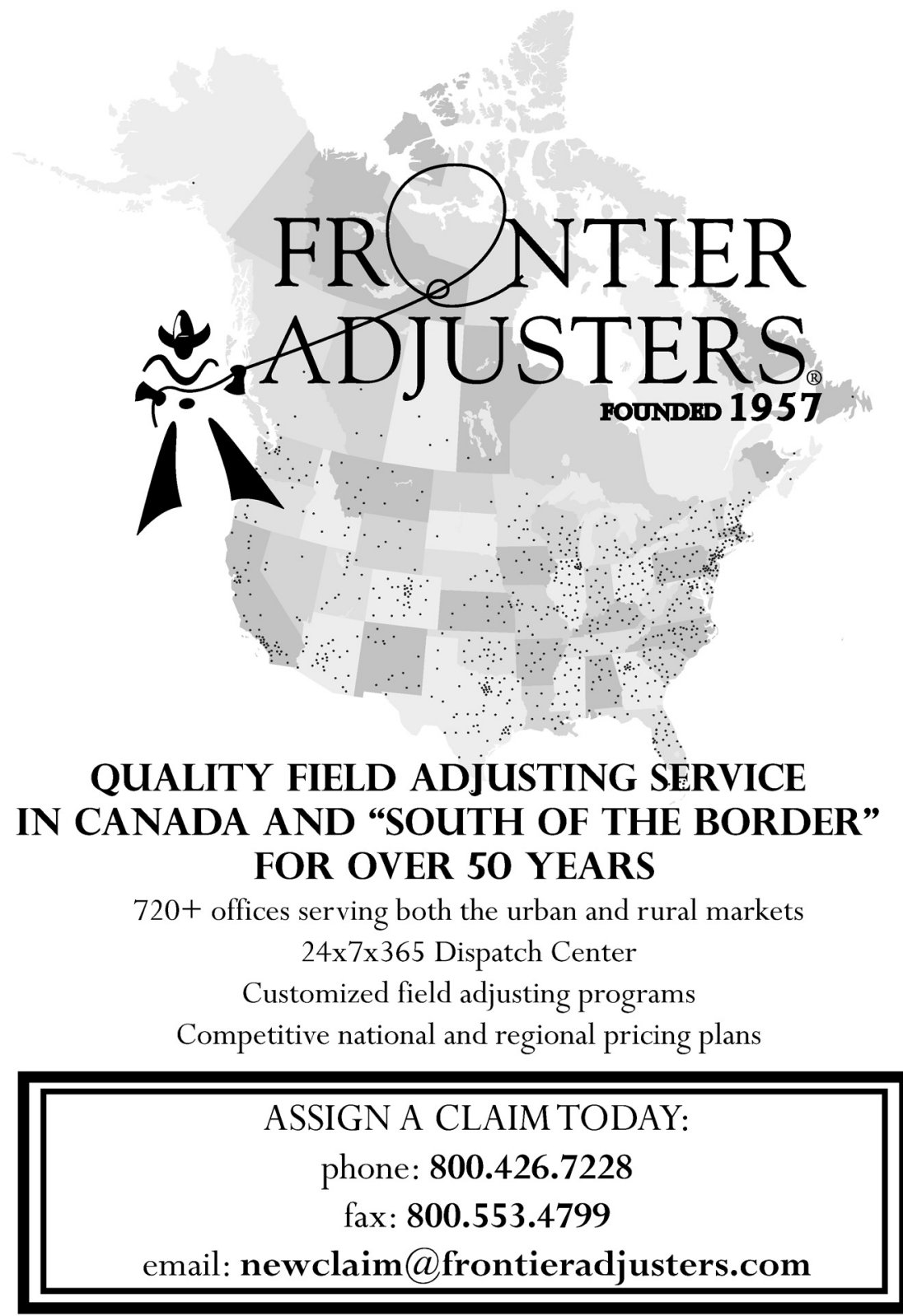

For more information, contact Milo Bolender, SeniorVice President 877.392.6278 ext. 15 milo.bolender@frontieradjusters.com 